\title{
Gastric Bypass Promotes More Lipid Mobilization Than a Similar Weight Loss Induced by Low-Calorie Diet
}

\author{
Joel Kullberg, ${ }^{1}$ Magnus Sundbom, ${ }^{2}$ Arvo Haenni, ${ }^{3}$ Susanne Freden, ${ }^{3}$ Lars Johansson, ${ }^{1}$ \\ Peter Börnert, ${ }^{4}$ Anders Ahlström, ${ }^{2}$ Håkan Ahlström, ${ }^{1}$ and Anders Karlsson ${ }^{5}$ \\ ${ }^{1}$ Department of Radiology, Uppsala University, 75185 Uppsala, Sweden \\ ${ }^{2}$ Department of Surgery, Uppsala University, 75185 Uppsala, Sweden \\ ${ }^{3}$ Department of Public Health and Caring Sciences, Uppsala University, 75185 Uppsala, Sweden \\ ${ }^{4}$ Philips Research Europe, D-22335 Hamburg, Germany \\ ${ }^{5}$ Department of Medical Sciences, Uppsala University, 75185 Uppsala, Sweden
}

Correspondence should be addressed to Joel Kullberg, joel.kullberg@radiol.uu.se

Received 2 August 2010; Revised 1 October 2010; Accepted 13 October 2010

Academic Editor: Francesco Saverio Papadia

Copyright (C) 2011 Joel Kullberg et al. This is an open access article distributed under the Creative Commons Attribution License, which permits unrestricted use, distribution, and reproduction in any medium, provided the original work is properly cited.

\begin{abstract}
Background. Recently, we found large reductions in visceral and subcutaneous fat one month after gastric bypass (GBP), without any change in liver fat content. Purpose. Firstly to characterize weight loss-induced lipid mobilization after one month with preoperative low-calorie diet (LCD) and a subsequent month following GBP, and secondly, to discuss the observations with reference to our previous published findings after GBP intervention alone. Methods. 15 morbidly obese women were studied prior to LCD, at GBP, and one month after GBP. Effects on metabolism were measured by magnetic resonance techniques and blood tests. Results. Body weight was similarly reduced after both months (mean: $-8.0 \mathrm{~kg}, n=13$ ). Relative body fat changes were smaller after LCD than after GBP $(-7.1 \pm 3.6 \%$ versus $-10 \pm 3.2 \%, P=.029, n=13)$. Liver fat fell during the LCD month $(-41 \%, P=.001, n=13)$ but was unaltered one month after GBP $(+12 \%)$. Conclusion. Gastric bypass seems to cause a greater lipid mobilization than a comparable LCD-induced weight loss. One may speculate that GBP-altered gastrointestinal signalling sensitizes adipose tissue to lipolysis, promoting the changes observed.
\end{abstract}

\section{Introduction}

Gastric bypass (GBP) surgery markedly reduces body weight with predominant losses of body fat and smaller reductions of lean body mass and bone mass [1]. The efficiency of GBP in treating morbid obesity is widely recognized, and its effect to improve glucose intolerance and diabetes is remarkable. In addition to the caloric restriction imposed by the operation, altered gastrointestinal hormonal signalling [2-4] is generally thought to contribute to the beneficial effect of GBP in resolving diabetes $[5,6]$.

In a recent study using magnetic resonance imaging (MRI) and magnetic resonance spectroscopy (MRS), we observed a larger relative reduction in visceral fat depot than subcutaneous fat at one month following GBP, and furthermore, an unexpected lack of change in liver fat [7]. At this time point, the morbidly obese subjects had lost an average of four BMI units, and the insulin sensitivity, as calculated by HOMA index, had improved by $34 \%$. Fasting concentrations of free fatty acids (FFA) and beta-hydroxybutyric acid were elevated, reflecting lipolysis and flux of free fatty acids to the liver. In general, an inverse relationship between liver fat content and insulin sensitivity has been described $[8,9]$. In this regard, the situation observed one month after GBP represents a notable disconnect.

Short periods of low-calorie diet (LCD) prior to gastric bypass are increasingly recommended by surgeons in order to preoperatively reduce body weight and liver volume and thereby facilitate the surgical procedure $[10,11]$. To provide further insights into lipid dynamics after GBP, we evaluated a group of morbidly obese women prior to one month of preoperative LCD, at surgery, and one month after the GBP. The metabolic balance was examined by blood tests, and changes of the lipid depots were analyzed with a novel 
MRI setup, including postprocessing and MRS. Significant differences between the two treatment periods with respect to the changes in total amount of body fat as well as liver fat were observed.

\section{Materials and Methods}

2.1. Subjects and Study Design. Fifteen morbidly obese women with the characteristics summarized in Table 1 were recruited from the waiting list for laparoscopic gastric bypass at the Department of Surgery, University Hospital in Uppsala, Sweden. None of the subjects had a specific hepatic disease disorder resulting in fatty liver or a history of alcohol abuse. The local ethics committee approved the study, and written consent was obtained from all subjects. This study was performed also to determine to what extent a one-month LCD treatment would reduce liver volume and facilitate the surgical procedures (to be published).

The study procedures were based on three main visits, separated by one month. At each of these visits, blood samples were drawn after overnight fasting. MR investigations were performed at the same day in a fed state. First visit: MRI/MRS was carried out in the forenoon, and the LCD treatment was initiated, after consultation with a dietician, during the afternoon. To increase motivation and thereby improve LCD compliance, a meeting with a dietician was held after approximately one week of LCD. Second visit: MRI/MRS was performed in the evening and the GBP the following day. Third visit: MRI/MRS was performed in the afternoon.

2.2. Low-Calorie Diet. LCD treatment (Modifast, Inpolin $\mathrm{AB}$, Stockholm) was initiated one month prior to the GBP. All participants received information and instructions from the same physician and a trained dietician. The LCD regimen ad modum Modifast, containing $30 \mathrm{E} \%$ protein, $49 \mathrm{E} \%$ carbohydrates, and $21 \mathrm{E} \%$ fat, was prescribed. Total calorie intake was set to total energy expenditure, as calculated by Harris-Benedict, minus $1000 \mathrm{kcal} /$ day. A lower limit of $860 \mathrm{kcal} /$ day was used. The resulting total calorie intake averaged $959 \pm 149 \mathrm{kcal} /$ day.

2.3. Surgery. Laparoscopic gastric bypass surgery was performed at the Department of Surgery, Uppsala University Hospital according to clinical routine [12]. A five-port technique with circular stapling of the gastrojejunostomy was used. The proximal jejunum was divided $30 \mathrm{~cm}$ distal to the ligament of Treitz, and a 70-cm Roux-limb was created. The small bowel continuity was restored by an enteroanastomosis. The left liver lobe was then elevated by an Endopaddle (Ethicon Endosurgery, Johnson\&Johnson, Cincinnati, $\mathrm{OH}$ ). The angle of His was opened as well as the bursa five $\mathrm{cm}$ distal to the gastroesophageal junction on the lesser curvature. The pouch was divided by a horizontal $45 \mathrm{~mm}$ cutting linear stapler and two vertical $60 \mathrm{~mm}$ rows. The anvil of the $25 \mathrm{~mm}$ circular stapler was passed transorally and placed in the right-angled corner in-between the two first stale lines. The Roux-limb was passed anticolic, antigastric and anastomosed to the pouch end-to-side by the circular stapler (Covidien, Norwalk, CT). Finally, the anastomosis was checked by air under water, and the portholes were closed. The patients were given preoperative antibiotics and thromboprophylaxis by subcutaneous low-molecular-weight heparin (LMWH) for 14 days. In each recruited patient, the laparoscopic gastric bypasses could be performed and the postoperative course was uneventful, except in one patient who had the enteroanastomosis corrected.

2.4. Blood Analyses. Blood was collected after an overnight fast, and serum and plasma were prepared and stored at $-70^{\circ} \mathrm{C}$ until analysis. Fasting plasma glucose, total cholesterol, low-density lipoprotein (LDL) cholesterol, highdensity lipoprotein (HDL) cholesterol, triglycerides (TG), free fatty acids (FFA), apolipoproteins $\mathrm{A} 1$ and $\mathrm{B}$, and liver enzymes were measured with routine laboratory techniques. Insulin was analyzed with an AutoDELFIA automatic immunoassay system (Wallac Oy, Turku, Finland). Growth hormone $(\mathrm{GH})$, glucagons, and NT-pBNP were determined with assays in routine use at Clinical Chemistry, Uppsala University Hospital. Beta-hydroxybutyrate was spectrophotometrically determined in plasma with an enzymatic endpoint method [13]. Leptin and adiponectin were analyzed in plasma samples as previously described [14]. The homeostasis model assessment (HOMA, mmol/L) index was calculated by multiplying fasting plasma glucose $\mathrm{mmol} / \mathrm{L}$ and fasting insulin $\mathrm{mU} / \mathrm{L}$ and then dividing by 22.5 [15].

2.5. Magnetic Resonance Acquisition. The MR measurements were performed using a 1.5T clinical scanner (Achieva; Philips Healthcare, Best, The Netherlands) modified to allow imaging during arbitrary table speed. A special $3 \mathrm{D}$ gradient echo sequence was used to collect three images with different echo times (TE) from each axial slice during continuous table motion [16]. Imaging parameters were as follow: TR $5.9 \mathrm{~ms}$, TE 1.36/3.22/5.09 ms, flip angle 3 degrees, elementary signal sampling field of view (FOV) (in motion direction) $112 \mathrm{~mm}$, virtual FOV $530 \times 377 \times 2000 \mathrm{~mm}^{3}$, and voxel size $2.07 \times 2.07 \times$ $8.00 \mathrm{~mm}^{3}$. The table speed was set to $6.5 \mathrm{~mm} / \mathrm{s}$ resulting in a whole-body scan time of $5 \mathrm{~min}, 15 \mathrm{sec}$. Shallow breathing was instructed during acquisition of the abdominal region to reduce potential respiration inducing motion artefacts. Subjects were imaged in supine position with the arms extended above the head.

To evaluate liver fat, single-volume localized ${ }^{1} \mathrm{H}$ spectroscopy was performed in a $3 \times 3 \times 3 \mathrm{~cm}^{3}$ volume of interest positioned in the right liver lobe, avoiding major vessels and bile ducts. A PRESS acquisition was used with the parameters TR/TE, 3000/44 ms, with 16 excitations without water suppression and 32 with water suppression (1024 samples, $1000 \mathrm{~Hz}$ bandwidth) during free shallow breathing.

2.6. Magnetic Resonance Data Processing. Whole-body water and fat images were reconstructed using the multiecho image data as previously described [17]; see Figure 1. Visceral and abdominal subcutaneous adipose tissue (VAT and SAT) was automatically measured from the reconstructed water 
TABLE 1: Subject characteristics of the 15 females at baseline and after one month of low-calorie diet (LCD) and one month after gastric bypass (GBP).

\begin{tabular}{|c|c|c|c|c|c|}
\hline & \multirow{2}{*}{$\begin{array}{c}\text { Baseline } \\
\text { Mean } \pm \text { SD }\end{array}$} & \multirow{2}{*}{$\begin{array}{c}\text { Post LCD } \\
\text { Mean } \pm \text { SD }\end{array}$} & \multicolumn{3}{|c|}{ Post GBP } \\
\hline & & & $P$ value & Mean \pm SD & $P$ value \\
\hline Age (years) & $34.7 \pm 7.88$ & & & & \\
\hline Weight (kg) & $121.3 \pm 13.4$ & $113.9 \pm 12.0$ & $<.001$ & $105.8 \pm 12.0$ & $<.001$ \\
\hline $\operatorname{BMI}\left(\mathrm{kg} / \mathrm{m}^{2}\right)$ & $42.9 \pm 3.02$ & $40.3 \pm 2.93$ & $<.001$ & $37.4 \pm 2.99$ & $<.001$ \\
\hline Total fat Volume (L) & $69.3 \pm 7.55^{\mathrm{a}}$ & $64.3 \pm 6.85^{\mathrm{a}}$ & $<.001$ & $58.0 \pm 7.65^{\mathrm{a}}$ & $<.001$ \\
\hline Total water Volume (L) & $42.9 \pm 4.53^{\mathrm{a}}$ & $40.8 \pm 3.82^{\mathrm{a}}$ & $<.001$ & $38.8 \pm 4.44^{\mathrm{a}}$ & $<.001$ \\
\hline VAT $(\mathrm{L})$ & $5.31 \pm 0.97^{\mathrm{a}}$ & $4.91 \pm 0.88^{\mathrm{a}}$ & .002 & $4.39 \pm 0.73^{\mathrm{a}}$ & $<.001$ \\
\hline SAT abd (L) & $21.3 \pm 2.93^{\mathrm{a}}$ & $19.8 \pm 2.73^{\mathrm{a}}$ & .003 & $17.8 \pm 3.10^{\mathrm{a}}$ & $<.001$ \\
\hline Liver fat (\%) & $9.72 \pm 6.31^{\mathrm{a}}$ & $5.69 \pm 4.24^{\mathrm{a}}$ & .001 & $5.89 \pm 3.93^{\mathrm{a}}$ & .736 \\
\hline Liver volume (L) & $2.17 \pm 0.38^{\mathrm{a}}$ & $1.90 \pm 0.23^{\mathrm{a}}$ & .001 & $1.89 \pm 0.28^{\mathrm{a}}$ & .841 \\
\hline Liver fat Volume (mL) & $218 \pm 154$ & $107 \pm 78.0$ & $<.001$ & $111 \pm 70.8$ & .376 \\
\hline Hemoglobin $(\mathrm{g} / \mathrm{L})$ & $139 \pm 7.54$ & $140 \pm 7.26$ & .845 & $136 \pm 6.77$ & .099 \\
\hline $\operatorname{EVF}(\%)$ & $41.2 \pm 2.40$ & $40.8 \pm 2.51$ & .458 & $39.3 \pm 2.23$ & .115 \\
\hline $\mathrm{Na}(\mathrm{mmol} / \mathrm{L})$ & $136 \pm 0.99$ & $137 \pm 1.64$ & .041 & $139 \pm 1.62$ & .007 \\
\hline $\mathrm{K}(\mathrm{mmol} / \mathrm{L})$ & $3.95 \pm 0.20$ & $3.67 \pm 0.25$ & .009 & $3.65 \pm 0.23$ & .793 \\
\hline Creatinine (umol/L) & $58.9 \pm 3.75$ & $65.9 \pm 6.34$ & .000 & $58.7 \pm 5.90$ & .003 \\
\hline $\operatorname{Albumin}(\mathrm{g} / \mathrm{L})$ & $41.3 \pm 2.26$ & $44.5 \pm 3.23$ & .001 & $43.3 \pm 2.72$ & .221 \\
\hline ALT (ukat/L) & $0.43 \pm 0.15$ & $0.93 \pm 0.60$ & .007 & $0.57 \pm 0.26$ & .015 \\
\hline AST (ukat/L) & $0.47 \pm 0.11$ & $0.62 \pm 0.23$ & .045 & $0.48 \pm 0.12$ & .034 \\
\hline GT $(\mu \mathrm{kat} / \mathrm{L})$ & $0.65 \pm 0.72$ & $0.74 \pm 0.81$ & .119 & $0.53 \pm 0.28$ & .179 \\
\hline Glucose (mmol/L) & $5.14 \pm 0.67$ & $4.73 \pm 0.83$ & .005 & $5.03 \pm 0.49$ & .082 \\
\hline Insulin (mU/L) & $22.9 \pm 7.82$ & $17.1 \pm 8.15$ & $<.001$ & $13.3 \pm 5.52$ & .096 \\
\hline HOMA index & $5.32 \pm 2.18$ & $3.63 \pm 1.93$ & $<.001$ & $2.99 \pm 1.33$ & .241 \\
\hline Growth hormone (ug/L) & $0.46 \pm 0.52$ & $1.05 \pm 0.97$ & .008 & $1.49 \pm 1.11$ & .146 \\
\hline Glucagon (pmol/L) & $73.4 \pm 20.8$ & $69.4 \pm 17.9$ & .149 & $75.8 \pm 18.2$ & .024 \\
\hline $\mathrm{BNP}(\mathrm{ng} / \mathrm{L})$ & $44.7 \pm 27.4$ & $46.3 \pm 28.4$ & .847 & $93.7 \pm 71.5$ & .011 \\
\hline Leptin (mg/L) & $17.4 \pm 4.91$ & $12.8 \pm 8.43$ & .000 & $10.3 \pm 3.29$ & .001 \\
\hline Adiponectin (Ug/mL) & $7.49 \pm 2.97$ & $8.37 \pm 8.43$ & .302 & $8.13 \pm 3.56$ & .662 \\
\hline Cholesterol (mmol/L) & $4.79 \pm 1.14$ & $4.43 \pm 1.05$ & .002 & $4.29 \pm 0.92$ & .349 \\
\hline $\mathrm{HDL}(\mathrm{mmol} / \mathrm{L})$ & $1.08 \pm 0.19$ & $0.93 \pm 0.15$ & .001 & $0.95 \pm 0.19$ & .550 \\
\hline $\mathrm{LDL}(\mathrm{mmol} / \mathrm{L})$ & $3.07 \pm 0.96$ & $2.85 \pm 1.05$ & .125 & $2.64 \pm 0.84$ & .145 \\
\hline LDL/HDL & $2.93 \pm 1.10$ & $3.27 \pm 1.44$ & .092 & $2.95 \pm 1.05$ & .094 \\
\hline Triglycerides (mmol/L) & $2.17 \pm 1.28$ & $1.80 \pm 0.76$ & .255 & $1.80 \pm 0.54$ & 1.000 \\
\hline $\operatorname{ApoA1}(g / L)$ & $1.33 \pm 0.14$ & $1.10 \pm 0.12$ & $<.001$ & $1.11 \pm 0.11$ & .829 \\
\hline ApoB (g/L) & $0.96 \pm 0.32$ & $0.89 \pm 0.28$ & .048 & $0.88 \pm 0.25$ & .775 \\
\hline ApoB/ApoA1 & $0.73 \pm 0.25$ & $0.82 \pm 0.28$ & .014 & $0.79 \pm 0.23$ & .290 \\
\hline $\mathrm{FFA}(\mathrm{mmol} / \mathrm{L})$ & $0.58 \pm 0.23$ & $0.85 \pm 0.33$ & .011 & $0.89 \pm 0.28$ & .739 \\
\hline Beta-hydroxybutyrate (mmol/L) & $0.07 \pm 0.05$ & $0.31 \pm 0.28$ & .007 & $0.34 \pm 0.22$ & .613 \\
\hline
\end{tabular}

${ }^{a}$ Data from the 13 subjects who completed the MR investigations. BMI: body mass index, VAT: visceral adipose tissue volume, SAT: subcutaneous adipose tissue volume in the abdominal subvolume, EVF: erythrocyte volume fraction. ALT: alanine transaminase, AST: aspartate aminotransferase, GT: gamma glutamyltransferase, BNP: B-type natriuretic peptide, FFA: free fatty acids.

Statistical significance evaluated from baseline to post-LCD, and post-LCD to post-GBP.

and fat images as previously described [16]. Coefficients of variation $(\mathrm{CVs})$ of repeated investigations have previously been determined to be $2.3 \% \pm 2.6 \%$ and $2.3 \% \pm 2.1 \%$, for VAT and SAT, respectively. Estimates of total fat and water volumes were calculated by summing the signals in the fat and water fraction images, respectively [16]; see Figure 1. To reduce the effect from differences in the amount of arms and feet included in the image volumes only, manually determined subvolumes (from the top of the head to the axial slice above the feet with "smallest areas") were analyzed. The fat volume is derived mainly from adipose tissues while the water volume originates mainly from lean tissue.

Spectroscopy data was analyzed using jMRUI [18] (version 3.0; www.mrui.uab.es), employing water as internal 


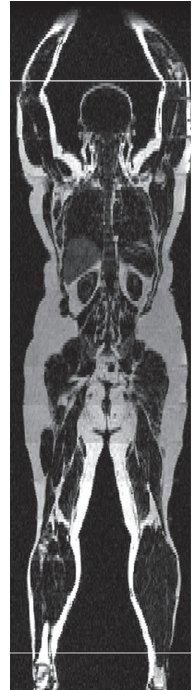

(a)

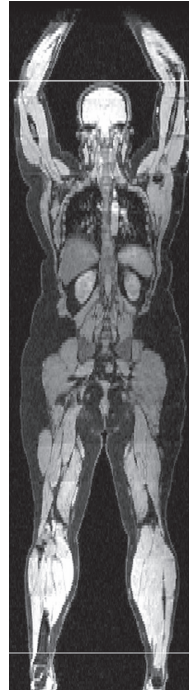

(b)

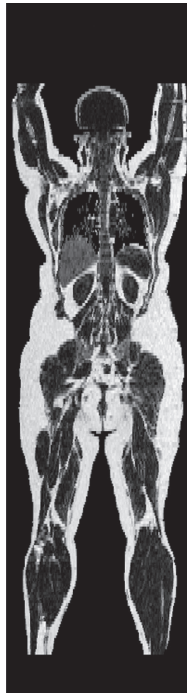

(c)

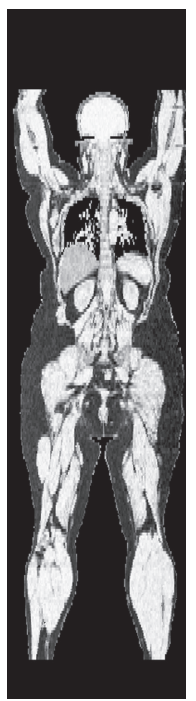

(d)

Figure 1: Illustration of image data employed from one subject included in the study. Reconstructed fat and water images are shown in (a) and (b), respectively. The horizontal lines delineate the subvolumes analysed in (c) and (d), where the fat- [fat/(fat+water)] and water-fraction [water/(fat+water)] images calculated and used to estimate total fat and water volumes are shown, respectively. Note that the intensity variations seen in (a) and (b) are removed by the use of fraction images. The intensity in each pixel estimates its absolute fat and water contents, and by integrating the pixel contents, total volumes are obtained. Note that fat infiltration of the liver (greyish and measured to approximately $25 \%$ ) can be seen in (c).

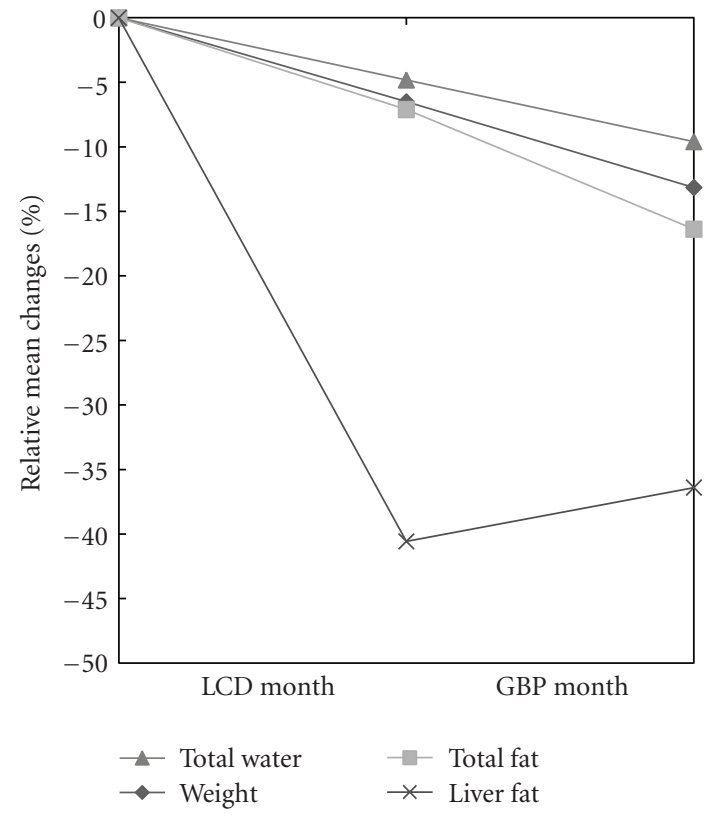

FIGURE 2: Relative mean changes of weight, total fat, total water, and liver fat during the LCD and the GBP months $(n=13)$.

reference, facilitating liver fat measures in percent. Spectral line intensities were determined by time domain fitting, using the nonlinear least-squares AMARES algorithm [19]. No spectral preprocessing was applied.

Liver volumes were assessed by manual segmentation in axial slices of the reconstructed water images by two

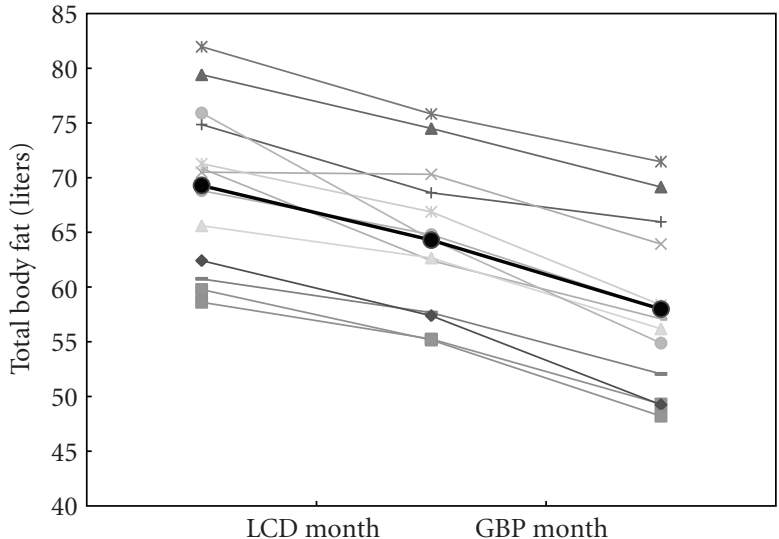

FIGURE 3: Individual total body fat volumes measured using prior to one month of LCD, at surgery, and at one month postGBP $(n=13)$. Mean body fat volume is illustrated by the thicker line.

experienced operators using the software ImageJ (version $1.40 \mathrm{~g}$, http://rsbweb.nih.gov/ij/). Average liver volumes were used. The liver fat assessment using MRS gives liver fat concentration (\%). If this concentration changes, one does not know if that is a result of change in liver fat content or if the total liver volume has changed for other reasons. Since liver volume was also assessed in this study, the total liver fat volume was calculated by multiplying concentration and volume.

2.7. Statistics Analysis. Two-sided, paired $t$-tests were used to test for differences between absolute values between the time 


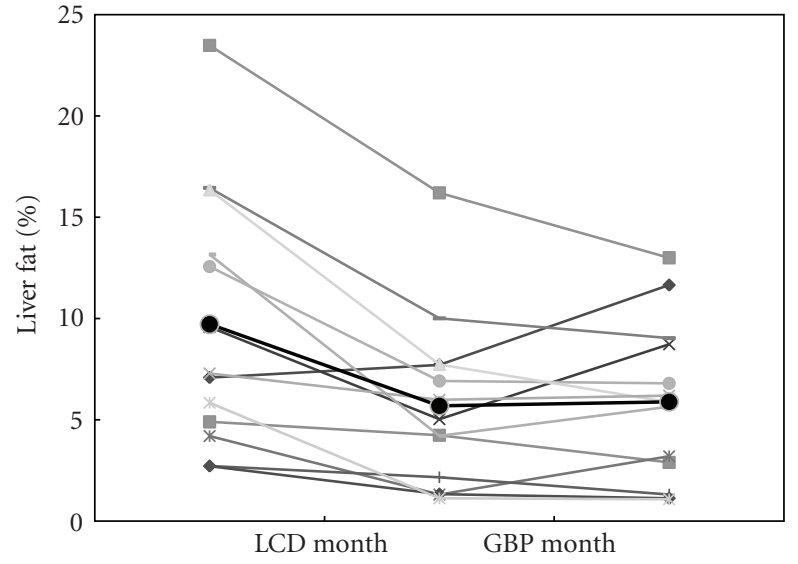

FIgURE 4: Liver fat concentrations (\%) determined using MRS at the three time points $(n=13)$. The thicker line illustrates mean liver fat concentration.

points in Table 1 and between relative changes in Table 2. $P$ values of $<.05$ were considered statistically significant.

\section{Results}

The patients lost comparable amounts of body weight during the two months, on average $7.47 \pm 2.59 \mathrm{~kg}$ during the first month with LCD and $8.09 \pm 1.70 \mathrm{~kg}$ during the postoperative month $(P=.497 / .148$, for absolute/relative changes, resp., $n=15$ ). The weight reductions in 13 subjects successfully analyzed with MRI/MRS were $8.03 \pm 2.28$ and $8.03 \pm 1.76 \mathrm{~kg}$, respectively. The relative decrease in total body fat was greater during the GBP month (from $-7.1 \% \pm 3.6 \%$ to $-10.0 \pm$ $3.2 \%, P=.029, n=13)$. The reductions in the visceral and abdominal subcutaneous fat depots were on average $-7.3 \%$ and $-6.6 \%$, respectively, after LCD and $-10.3 \%$ and $-10.3 \%$ after GBP. The estimated water volumes showed similar changes during the LCD and the GBP month, $-4.8 \%$ and $-5.0 \%$, respectively.

The measurements at the different time points are shown in Table 1 and the relative changes in Table 2. The MRI/MRS data is reported for the 13 subjects successfully analysed at all three time points. One subject cancelled all MR investigations and another subject cancelled her third. The relative mean changes in weight, total fat and water volumes and also in liver fat are shown in Figure 2. The absolute fat volumes and liver fat measurements are shown in Figures 3 and 4 , respectively.

Liver volume decreased significantly over the LCDmonth but not during the GBP month. Corresponding changes in liver fat were determined to be $-40.6 \% \pm 25.3 \%$, $(P=.001)$ and $+12.4 \% \pm 51.7 \%,(P=.736)$.

Biochemically, alterations in fasting glucose and insulin levels took place during the two periods, resulting in increased insulin sensitivity as reflected by the HOMA indices. Free fatty acids concentrations increased from 0.58 to $0.85 \mathrm{mmol} / \mathrm{L}$ after $\mathrm{LCD}$ and to $0.89 \mathrm{mmol} / \mathrm{L}$ one month after the operation. The beta-hydroxybutyrate concentrations increased by several folds during LCD, from a mean of
0.07 to $0.31 \mathrm{umol} / \mathrm{L}$ and remained elevated one month after surgery, $0.34 \mathrm{umol} / \mathrm{L}$.

The patients studied had, at baseline, cholesterol and apolipoprotein $\mathrm{A}$ and $\mathrm{B}$ within the normal reference ranges and slightly elevated triglycerides. After diet and surgery, changes within the reference ranges were noted. Leptin fell during both LCD and GBP. Adiponectin tended to increase after LCD and was not further altered over the postoperative month. Mean values of growth hormone prior to LCD, at surgery, and at one month after GBP were $0.46,1.05$, and $1.49 \mathrm{ug} / \mathrm{L}$, glucagon 73, 69, and $76 \mathrm{pmol} / \mathrm{L}$, and NT-pBNP 45, 46 , and $94 \mathrm{ng} / \mathrm{L}$, respectively.

Alanine transaminase (ALT) increased after LCD from 0.43 to $0.93 \mu \mathrm{kat} / \mathrm{L}$ and fell into the normal range to 0.57 the month after surgery. Aspartate aminotransferase (AST) and gamma glutamyltransferase (GT) showed similar patterns of lesser magnitude.

\section{Discussion}

The extent of weight loss after the month with LCD and that at the first month after GBP were similar, yet the mobilization of body fat was larger after the operation than after the LCD. Furthermore, the amount of liver fat was not lowered one month after GBP, which it was after the month of LCD. Free fatty acids and the beta-hydroxybuturate concentrations were elevated and tended to be higher one month after GBP, compared to after one month of LCD. Collectively, the findings indicate a more marked flux of fatty acids from the adipose tissues to the liver and subsequent incorporation into triglycerides during the month after GBP compared to the LCD month.

A limitation of the design used in this study is that the effects seen during the month after GBP are not only influenced by the GBP surgery but also by effects of the preoperative LCD. The restriction of the caloric intake during the preoperative LCD month most likely reduces the initial lipolytic effects seen after GBP. Despite this, the results from the current study indicate instead an increased lipolysis after GBP.

The observation of unchanged liver fat one month after surgery is in good agreement with our previous prospective report on lipid mobilization over a year-long period after GBP, in which at one month after surgery, there likewise was no change in liver fat, despite marked changes in subcutaneous and visceral depots [7]. The patients of the previous study were also of female gender and had similar age, weight, and BMI (35 years range 22-47, $122 \pm 13 \mathrm{~kg}$, and $43.7 \pm 4.1 \mathrm{~kg} / \mathrm{m}^{2}$, resp.) as the subjects of this study. Thereby, they can be regarded as a historical control group of obese subjects undergoing gastric bypass without a preoperative LCD period. These subjects lost, on average, $11.0 \mathrm{~kg}$ body weight and 8.4 liters of adipose tissue (also assessed using whole-body MRI) the first month after GBP. This should be compared to the reductions of $7.4 \mathrm{~kg}$ body weight and 5.0 liters of adipose tissue measured after the LCD month in the current study. It seems likely that the lesser degree of weight loss during the month after GBP in the present study 
TABLE 2: Relative changes (\%) over the low-calorie diet (LCD) and postGBP periods.

\begin{tabular}{|c|c|c|c|}
\hline & LCD month & GBP month & $P$ value \\
\hline Weight / BMI & $-6.08 \pm 1.77$ & $-7.17 \pm 1.60$ & .148 \\
\hline Total Fat Volume & $-7.11 \pm 3.58^{\mathrm{a}}$ & $-10.0 \pm 3.19^{\mathrm{a}}$ & .029 \\
\hline Total Water Volume & $-4.82 \pm 2.29^{\mathrm{a}}$ & $-4.98 \pm 2.69^{\mathrm{a}}$ & .898 \\
\hline VAT & $-7.28 \pm 6.92^{\mathrm{a}}$ & $-10.3 \pm 6.40^{\mathrm{a}}$ & .326 \\
\hline SAT abd & $-6.55 \pm 6.73^{\mathrm{a}}$ & $-10.3 \pm 5.32^{\mathrm{a}}$ & .171 \\
\hline Liver Fat & $-40.6 \pm 25.3^{\mathrm{a}}$ & $+12.4 \pm 51.7^{\mathrm{a}}$ & .011 \\
\hline Liver Volume & $-12.0 \pm 7.54^{\mathrm{a}}$ & $-0.40 \pm 8.33^{\mathrm{a}}$ & .013 \\
\hline Liver Fat Volume & $-47.2 \pm 24.5$ & $13.6 \pm 55.9$ & .006 \\
\hline Hemoglobin & $0.27 \pm 3.73$ & $-2.72 \pm 6.17$ & .195 \\
\hline EVF & $-0.87 \pm 5.04$ & $-3.27 \pm 7.81$ & .409 \\
\hline $\mathrm{Na}$ & $0.79 \pm 1.34$ & $1.32 \pm 1.62$ & .473 \\
\hline K & $-6.78 \pm 8.83$ & $-0.19 \pm 10.1$ & .184 \\
\hline Creatinine & $11.9 \pm 8.32$ & $-10.4 \pm 11.0$ & $<.001$ \\
\hline Albumin & $7.84 \pm 7.08$ & $-2.32 \pm 7.90$ & .009 \\
\hline ALT & $138 \pm 180$ & $-26.5 \pm 29.3$ & .007 \\
\hline AST & $43.1 \pm 88.2$ & $-16.4 \pm 25.5$ & .047 \\
\hline GT & $14.9 \pm 38.1$ & $-3.81 \pm 39.3$ & .282 \\
\hline Glucose & $-8.01 \pm 8.53$ & $8.01 \pm 13.2$ & .008 \\
\hline Insulin & $-27.0 \pm 20.1$ & $-12.5 \pm 43.8$ & .339 \\
\hline HOMA index & $-32.2 \pm 22.2$ & $-2.47 \pm 60.2$ & .141 \\
\hline Growth hormone & $348 \pm 621$ & $422 \pm 1070$ & .835 \\
\hline Glucagon & $-3.54 \pm 17.1$ & $10.6 \pm 15.3$ & .055 \\
\hline $\mathrm{BNP}$ & $34.1 \pm 97.5$ & $146 \pm 173$ & .078 \\
\hline Leptin & $-25.7 \pm 14.6$ & $-18.3 \pm 19.9$ & .182 \\
\hline Adiponectin & $16.0 \pm 47.3$ & $76.8 \pm 310$ & .504 \\
\hline Cholesterol & $-7.11 \pm 7.31$ & $-2.13 \pm 11.4$ & .269 \\
\hline $\mathrm{HDL}$ & $-13.3 \pm 12.5$ & $2.46 \pm 13.3$ & .023 \\
\hline LDL & $-6.91 \pm 17.1$ & $-5.23 \pm 15.1$ & .830 \\
\hline LDL/HDL & $12.4 \pm 21.2$ & $-7.36 \pm 16.6$ & .043 \\
\hline Triglycerides & $-6.01 \pm 37.8$ & $7.10 \pm 29.7$ & .409 \\
\hline Ap-lipA1 & $-16.6 \pm 8.11$ & $1.09 \pm 9.80$ & .001 \\
\hline Ap-lipB & $-5.97 \pm 13.0$ & $0.15 \pm 10.8$ & .268 \\
\hline $\mathrm{ApB} / \mathrm{A} 1$ & $15.3 \pm 20.6$ & $-2.30 \pm 14.4$ & $.050(.0497)$ \\
\hline FFA & $74.4 \pm 109$ & $20.9 \pm 589$ & .186 \\
\hline Beta-hydroxybutyrate & $482 \pm 651$ & $103 \pm 220$ & .080 \\
\hline
\end{tabular}

a Data from the 13 subjects who completed the MR investigations. BMI: body mass index, VAT: visceral adipose tissue volume, SAT: subcutaneous adipose tissue volume in the abdominal subvolume, EVF: erythrocyte volume fraction. ALT: alanine transaminase, AST: aspartate aminotransferase, GT: gamma glutamyltransferase, BNP: B-type natriuretic peptide, FFA: free fatty acids.

Statistical significance evaluated from differences in relative changes over the LCD and GBP months.

is influenced by the prior weight loss that took place during the preoperative LCD month.

The similar weight losses measured in this study suggest that the caloric intakes over the two periods were comparable. Average caloric intake three to six months after gastric bypass surgery has been estimated to be $960-1000 \mathrm{kcal} /$ day $[20,21]$, that is, close to that of the LCD employed (average $959 \mathrm{kcal} /$ day). The patients were advised a diet with an energy content and macronutrient composition similar to that of the LCD. After an operation, patients typically take multiple, small meals in order to lower a risk of dumping and/or postprandial hypoglycemic episodes. We did not collect dietary records in attempts to calculate detailed energy, protein, lipid, and carbohydrate intake.

To account for the larger reduction in fat after GBP compared to the LCD period but similar weight losses during the two periods, a somewhat larger reduction in nonfat compartments should have taken place during the LCD month. With the MRI technique used, only two compartments are visualized as images generated from protons in fat and water molecules. The fat volumes primarily reflect the adipose tissue even though bone marrow and fatty infiltrated tissues/organs also contribute. The water volumes reflect the nonfat lean tissue of muscles, organs, and brain. Bone 
marrow and water content in adipose tissue also contribute. In this study, the change in water volumes did not differ between the LCD and GBP months, in contrast to the change in fat volumes. A limitation of our study is that we did not perform any measurements by DEXA, which would provide information on changes in lean tissue and bone.

There was an increase in liver enzymes during LCD and a trend towards normalization over the month following the operation. In general, morbid obesity is associated with some degree of steatohepatitis and elevation of liver enzymes, changes that improve upon long-term weight loss [22]. Marked diet-induced weight loss over shorter periods of time has been found to increase liver enzymes $[23,24]$ by mechanisms that are not fully understood [25]. In some studies, the increase in enzymes has been transitory and suggested to reflect an adaptation of the hepatocytes. In this study, the difference in enzyme levels one month after LCD compared to one month after GBP might reflect such adaptation, as the daily average intake and composition of nutrients supposedly were similar during the two periods. In support of such notion, we have observed that patients operated with gastric bypass without a preoperative LCD treatment and examined one month after the operation displayed elevated liver enzymes (unpublished).

Any caloric restriction causes a breakdown of fat, driven by hormone-sensitive lipase in adipocytes and by lipoprotein lipase in heart and skeletal muscles. Lipolysis in white adipose tissue is mainly controlled by the antilipolytic effect of insulin and a stimulatory effect of norepinephrine released from sympathetic nerve endings and acting via beta-adrenergic receptors [26]. Lipolysis is also influenced by humoural factors such as circulating catecholamines, growth hormone, thyroid hormones, and glucagon. Recently, natriuretic peptides have been added to the list of lipolytic hormones [27]. In this study, GH baseline concentrations increased throughout and thereby conceivably contributed to promote lipolysis. Increases in GH levels after GBP have been described by us [28] and others [29]. The BNP levels were unchanged during the LCD month while they were seen to increase during the GBP month. We are not aware of any prior reports of BNP levels determined after gastric surgery.

In a recent report, centrally administered GLP-1 was found to stimulate sympathetic flow and lipolysis of body fat [30]. An increased secretion of GLP-1 is a prominent finding in patients who have been operated with gastric bypass [4, 31]. Hypothetically, a central GLP-1 mechanism might play a role for the enhanced lipolysis after GBP. Glucagon stimulates glycogenolysis and fatty acid oxidation in the liver and has been shown also to stimulate lipolysis in adipocytes $[32,33]$. In patients operated with GBP, a remarkable response with a rise in glucagon following food intake has been observed $[34,35]$. Possibly, postprandial increases in glucagon levels might contribute to the enhanced mobilization of body fat after GBP surgery.

In conclusion, the mechanism behind an enhanced lipolysis after GBP seems multifactorial. The caloric restriction imposed by the surgical procedure is the main driver of lipolysis, to which altered gastrointestinal signalling, for example, meal-stimulated increases in GLP-1 and glucagon, and sympathetic nerve outflow to the adipose tissue in autonomic nerves conceivably contribute. It is likely that FFAs are utilized as energy source in heart and skeletal muscle and lower the need for glucose, which in turn lowers insulin secretion in the nonfed state and thereby promotes lipid mobilization. Lipolysis might also be stimulated by increased fasting levels of lipolytic hormones, for example, growth hormone, BNP, catecholamines. An increased flux of FFA from adipose tissues depots would promote the maintained triglyceride levels in the liver one month after GBP. To obtain further insights into the phenomenon of enhanced lipolysis, studies of diurnal hormone and catecholamine dynamics could be of interest.

\section{Acknowledgments}

The authors thank Margareta Ericson for expert technical assistance and Elisabeth Olsson for excellent care and samplings. The Modifast LCD was bestowed by Inpolin AB. This study was supported by grants from the Swedish Research Council and the Family Ernfors Fund.

\section{Conflict of Interests}

The authors declare that they have no conflicts of interests.

\section{References}

[1] K. C. Zalesin, B. A. Franklin, M. A. Lillystone et al., "Differential loss of fat and lean mass in the morbidly obese after bariatric surgery," Metabolic Syndrome and Related Disorders, vol. 8, no. 1, pp. 15-20, 2010.

[2] C. M. Borg, C. W. Le Roux, M. A. Ghatei, S. R. Bloom, A. G. Patel, and S. J. B. Aylwin, "Progressive rise in gut hormone levels after Roux-en-Y gastric bypass suggests gut adaptation and explains altered satiety," British Journal of Surgery, vol. 93, no. 2, pp. 210-215, 2006.

[3] C. Holdstock, B. Zethelius, M. Sundbom, F. A. Karlsson, and B. Edén Engström, "Postprandial changes in gut regulatory peptides in gastric bypass patients," International Journal of Obesity, vol. 32, no. 11, pp. 1640-1646, 2008.

[4] H. E. Bays, B. Laferrère, J. Dixon et al., "Adiposopathy and bariatric surgery: is 'sick fat' a surgical disease?" International Journal of Clinical Practice, vol. 63, no. 9, pp. 1285-1300, 2009.

[5] A. A. Gumbs, I. M. Modlin, and G. H. Ballantyne, "Changes in insulin resistance following bariatric surgery: role of caloric restriction and weight loss," Obesity Surgery, vol. 15, no. 4, pp. 462-473, 2005.

[6] F. Rubino, P. R. Schauer, L. M. Kaplan, and D. E. Cummings, "Metabolic surgery to treat type 2 diabetes: clinical outcomes and mechanisms of action," Annual Review of Medicine, vol. 61, pp. 393-411, 2010.

[7] L. Johansson, M. Roos, J. Kullberg et al., "Lipid mobilization following Roux-en-Y gastric bypass examined by magnetic resonance imaging and spectroscopy," Obesity Surgery, vol. 18, no. 10, pp. 1297-1304, 2008.

[8] D. E. Kelley, T. M. McKolanis, R. A. F. Hegazi, L. H. Kuller, and S. C. Kalhana, "Fatty liver in type 2 diabetes mellitus: relation to regional adiposity, fatty acids, and insulin resistance," American Journal of Physiology, vol. 285, no. 4, pp. E906-E916, 2003. 
[9] H. Yki-Jarvinen, "Fat in the liver and insulin resistance," Annals of Medicine, vol. 37, no. 5, pp. 347-356, 2005.

[10] R. C. Liu, A. A. Sabnis, C. Forsyth, and B. Chand, "The effects of acute preoperative weight loss on laparoscopic Roux-en-Y gastric bypass," Obesity Surgery, vol. 15, no. 10, pp. 1396-1402, 2005.

[11] R. S. Alami, J. M. Morton, R. Schuster et al., "Is there a benefit to preoperative weight loss in gastric bypass patients? A prospective randomized trial," Surgery for Obesity and Related Diseases, vol. 3, no. 2, pp. 141-145, 2007.

[12] M. Sundbom and S. Gustavsson, "Randomized clinical trial of hand-assisted laparoscopic versus open Roux-en-Y gastric bypass for the treatment of morbid obesity," British Journal of Surgery, vol. 91, no. 4, pp. 418-423, 2004.

[13] K. E. Wildenhoff, "A micro-method for the enzymatic determination of acetoacetate and 3-hydroxybutyrate in blood and urine," Scandinavian Journal of Clinical and Laboratory Investigation, vol. 25, no. 2, pp. 171-179, 1970.

[14] C. Holdstock, B. E. Engström, M. Öhrvall, L. Lind, M. Sundbom, and F. A. Karlsson, "Ghrelin and adipose tissue regulatory peptides: effect of gastric bypass surgery in obese humans," Journal of Clinical Endocrinology and Metabolism, vol. 88, no. 7, pp. 3177-3183, 2003.

[15] D. R. Matthews, J. P. Hosker, A. S. Rudenski, B. A. Naylor, D. F. Treacher, and R. C. Turner, "Homeostasis model assessment: insulin resistance and beta-cell function from fasting plasma glucose and insulin concentrations in man," Diabetologia, vol. 28, no. 7, pp. 412-419, 1985.

[16] J. Kullberg, L. Johansson, H. Ahlström et al., "Automated assessment of whole-body adipose tissue depots from continuously moving bed MRI: a feasibility study," Journal of Magnetic Resonance Imaging, vol. 30, no. 1, pp. 185-193, 2009.

[17] J. Berglund, L. Johansson, H. Ahlström, and J. Kullberg, "Three-point Dixon method enables whole-body water and fat imaging of obese subjects," Magnetic Resonance in Medicine, vol. 63, no. 6, pp. 1659-1668, 2010.

[18] A. Naressi, C. Couturier, J. M. Devos et al., "Java-based graphical user interface for the MRUI quantitation package," Magnetic Resonance Materials in Physics, Biology and Medicine, vol. 12, no. 2-3, pp. 141-152, 2001.

[19] L. Vanhamme, A. Van Den Boogaart, and S. Van Huffel, "Improved method for accurate and efficient quantification of MRS data with use of prior knowledge," Journal of Magnetic Resonance, vol. 129, no. 1, pp. 35-43, 1997.

[20] F. Carrasco, K. Papapietro, A. Csendes et al., "Changes in resting energy expenditure and body composition after weight loss following Roux-en-Y gastric bypass," Obesity Surgery, vol. 17, no. 5, pp. 608-616, 2007.

[21] E. Bobbioni-Harsch, O. Huber, PH. Morel et al., "Factors influencing energy intake and body weight loss after gastric bypass," European Journal of Clinical Nutrition, vol. 56, no. 6, pp. 551-556, 2002.

[22] R. T. Wang, R. L. Koretz, and H. F. Yee Jr., "Is weight reduction an effective therapy for nonalcoholic fatty liver? A systematic review," American Journal of Medicine, vol. 115, no. 7, pp. 554$559,2003$.

[23] R. Friis, N. D. Vaziri, F. Akbarpour, and A. Afrasiabi, "Effect of rapid weight loss with supplemented fasting on liver tests," Journal of Clinical Gastroenterology, vol. 9, no. 2, pp. 204-207, 1987.

[24] C. Gasteyger, T. M. Larsen, F. Vercruysse, and A. Astrup, "Effect of a dietary-induced weight loss on liver enzymes in obese subjects," American Journal of Clinical Nutrition, vol. 87, no. 5, pp. 1141-1147, 2008.

[25] M. C. Ryan, F. Abbasi, C. Lamendola, S. Carter, and T. L. McLaughlin, "Serum alanine aminotransferase levels decrease further with carbohydrate than fat restriction in insulinresistant adults," Diabetes Care, vol. 30, no. 5, pp. 1075-1080, 2007.

[26] M. A. Van Baak, "The peripheral sympathetic nervous system in human obesity," Obesity Reviews, vol. 2, no. 1, pp. 3-14, 2001.

[27] A. L. Birkenfeld, P. Budziarek, M. Boschmann et al., "Atrial natriuretic peptide induces postprandial lipid oxidation in humans," Diabetes, vol. 57, no. 12, pp. 3199-3204, 2008.

[28] B. E. Engström, P. Burman, C. Holdstock, M. Öhrvall, M. Sundbom, and F. A. Karlsson, "Effects of gastric bypass on the GH/IGF-I axis in severe obesity — and a comparison with GH deficiency," European Journal of Endocrinology, vol. 154, no. 1, pp. 53-59, 2006.

[29] M. H. Rasmussen, A. Hvidberg, A. Juul et al., "Massive weight loss restores 24-hour growth hormone release profiles and serum insulin-like growth factor-I levels in obese subjects," Journal of Clinical Endocrinology and Metabolism, vol. 80, no. 4, pp. 1407-1415, 1995.

[30] R. Nogueiras, D. Pérez-Tilve, C. Veyrat-Durebex et al., "Direct control of peripheral lipid deposition by CNS GLP-1 receptor signaling is mediated by the sympathetic nervous system and blunted in diet-induced obesity," Journal of Neuroscience, vol. 29, no. 18, pp. 5916-5925, 2009.

[31] R. Morínigo, V. Moizé, M. Musri et al., "Glucagon-like peptide-1, peptide YY, hunger, and satiety after gastric bypass surgery in morbidly obese subjects," Journal of Clinical Endocrinology and Metabolism, vol. 91, no. 5, pp. 1735-1740, 2006.

[32] J. E. Gerich, M. Lorenzi, and D. M. Bier, "Effects of physiologic levels of glucagon and growth hormone on human carbohydrate and lipid metabolism. Studies involving administration of exogenous hormone during suppression of endogenous hormone secretion with somatostatin," Journal of Clinical Investigation, vol. 57, no. 4, pp. 875-884, 1976.

[33] "Glucagon and Lipid Metabolism," in Glucagon: Molecular Physiology, Clinical and Therapeutic Implications, P. H. Lefèbvre and R. H. Unger, Eds., Pergammon, New York, NY, USA, 1972.

[34] A. B. Goldfine, E. C. Mun, E. Devine et al., "Patients with neuroglycopenia after gastric bypass surgery have exaggerated incretin and insulin secretory responses to a mixed meal," Journal of Clinical Endocrinology and Metabolism, vol. 92, no. 12, pp. 4678-4685, 2007.

[35] B. Laferrère, J. Teixeira, J. McGinty et al., "Effect of weight loss by gastric bypass surgery versus hypocaloric diet on glucose and incretin levels in patients with type 2 diabetes," Journal of Clinical Endocrinology and Metabolism, vol. 93, no. 7, pp. 2479-2485, 2008. 


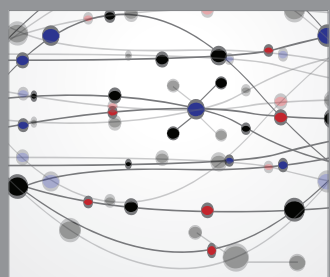

The Scientific World Journal
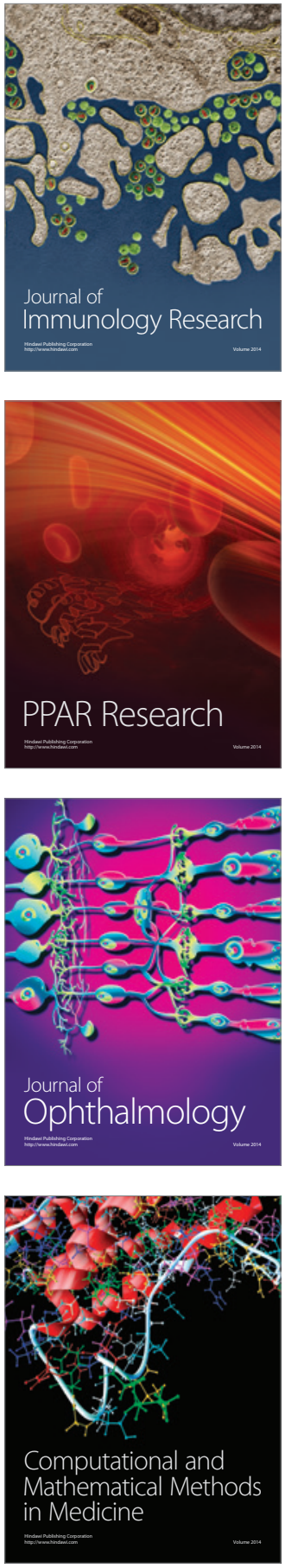

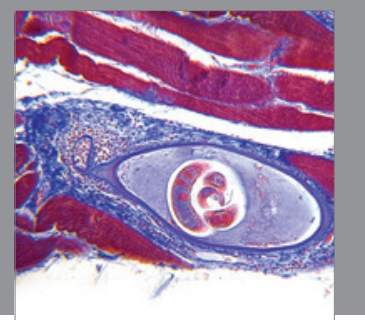

Gastroenterology

Research and Practice
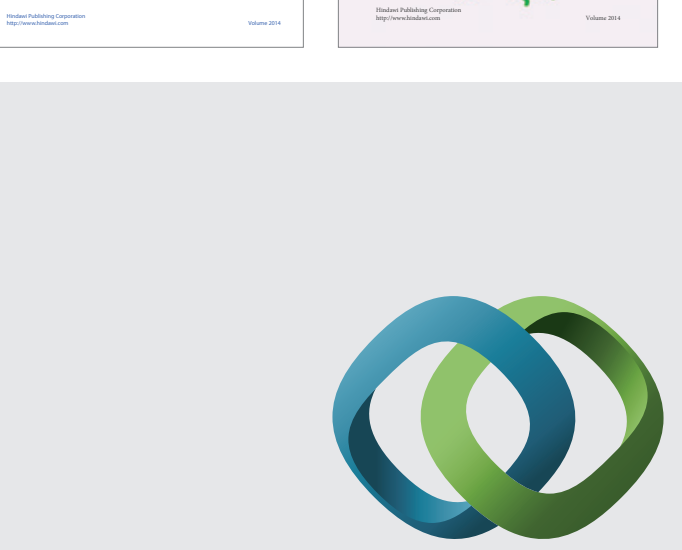

\section{Hindawi}

Submit your manuscripts at

http://www.hindawi.com
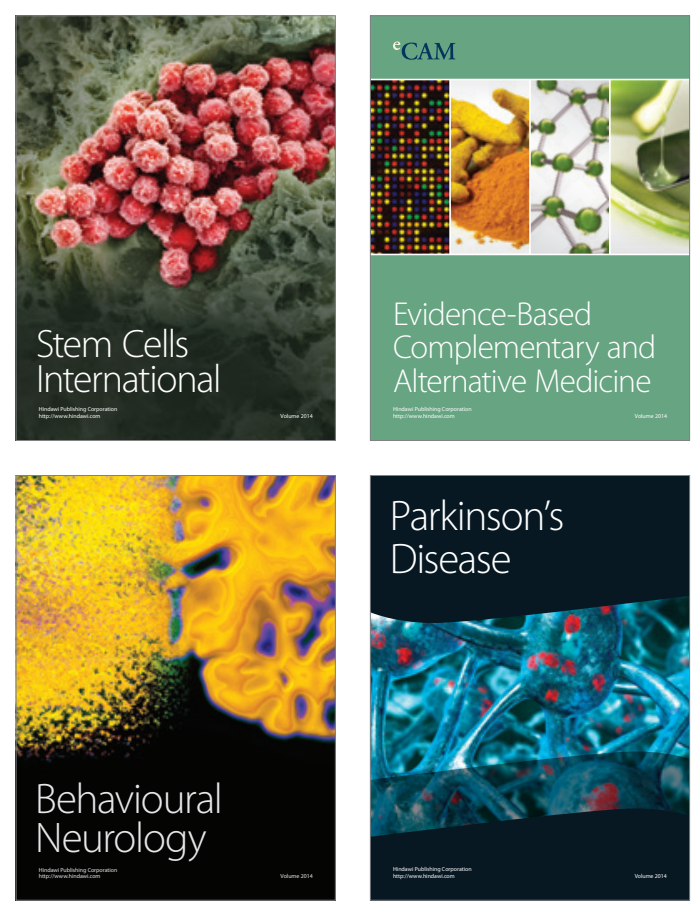

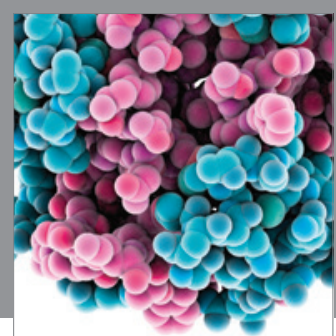

Journal of
Diabetes Research

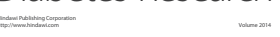

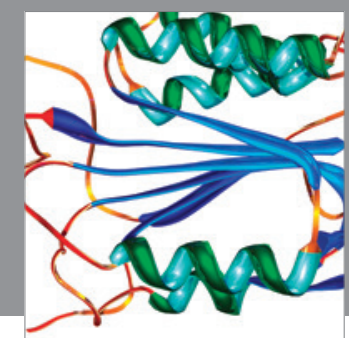

Disease Markers
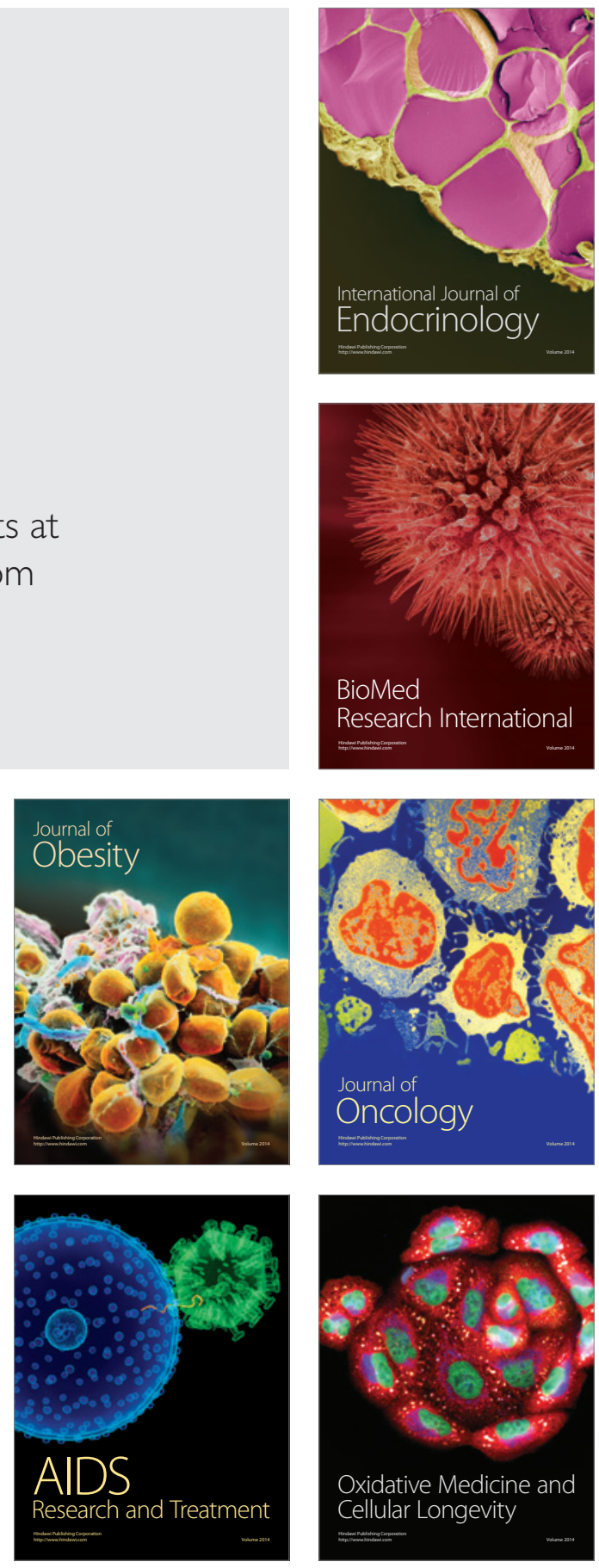